\title{
Trade and Location with Horizontal and Vertical Multi-Region Firms*
}

\author{
Karolina Ekholm $^{* *}$ and Rikard Forslid ${ }^{* * *}$
}

\begin{abstract}
$\underline{\text { Abstract }}$
This paper analyses the effect on agglomeration tendencies of allowing firms to become multi-region firms in a standard model of trade and location. More specifically, we introduce horizontal and vertical multi-region firms into the coreperiphery (CP) model developed by Krugman (1991). The introduction of horizontal multi-region firms dampens the strong agglomeration effects found in the $\mathrm{CP}$ model by making the range of trade costs for which the core-periphery equilibrium occurs smaller. The introduction of vertical multi-region firms that can separate the location of headquarter activities from the location of production has two counteracting effects. First, headquarters have a strong tendency to agglomerate, and, in this sense, agglomeration tendencies are strengthened. Second, actual production tends to be more spread out, and, in this sense, they are weakened.
\end{abstract}

JEL Classification: F12, F15, R12

Keywords: trade, location, agglomeration, multinational firms

\footnotetext{
* A first draft of this paper was circulated as a CEPR discussion paper (No. 1607) entitled "Agglomeration in a Core-Periphery Model with Vertically and Horizontally Integrated Firms". We would like to thank Richard Baldwin, Mattias Ganslandt, Jan Haaland, Karen Helene MidelfartKnarvik, Diego Puga, Luca Ricci, Paul Segerstrom, and Tony Venables for useful comments. Financial support from the Tore Browaldh Foundation, the Wallander-Hedelius Foundation, the Marianne and Marcus Wallenberg Foundation and the Craaford Foundation is gratefully acknowledged.

** The Research Institute of Industrial Economics (IUI). Address: IUI, P.O. Box 5501, S-114 85 Stockholm, Sweden. Phone: +46 878384 28, fax: +46 866179 69, e-mail: karolinae@iui.se
} 


\section{Introduction}

The recent literature on economic geography offers a theoretical basis for one common worry of politicians in peripheral regions, namely that industrial production has a tendency to agglomerate in central regions. For instance, in Krugman (1991) and Krugman and Venables (1995), the interaction between scale economies and transportation costs gives rise to linkages between firms and labour/customers or between the firms themselves via their demand for intermediate products. This, in turn, may at certain levels of trade costs produce a core-periphery structure where industrial production is concentrated in one region.

Models of this kind have been used in several studies to analyse the effects of regional integration on the location of industrial activity and income inequality between regions (for a survey, see Baldwin and Venables 1996). In these models, a production structure with dispersed industrial activity can be sustained with high trade costs, while low trade costs may induce complete agglomeration of industrial activity. Therefore, a straightforward implication is that integration in the form of reductions in trade costs can yield agglomeration and under certain circumstances increased inequality in real incomes.

However, the strong effects on the location of industrial activity in these models seem to some extent to be a consequence of the rather restrictive assumptions about the firm's production function. Scale economies are assumed only to be present at plant level, which implies that each variety of a differentiated product will be produced at a single location.

In a model developed by Markusen and Venables (1996), horizontally integrated firms are introduced into a general-equilibrium model by assuming that there are scale economies at both firm and plant level, implying that each variety will

\footnotetext{
*** Lund University and CEPR. Address: Department of Economics, Lund University, P.O. Box 7082, S-220 07 Lund, Sweden. Phone: +46 4622286 76, fax: +46 4622246 13, e-mail: rikard.forslid@nek.lu.se
} 
be produced by a single firm, but may be produced in several plants. That is, in this model, firms may choose to become multinationals. In an extension, Markusen and Venables (1996) show that the tendency for concentration of industrial activity may be weaker when we allow firms to set up production plants both at home and abroad. More specifically, they show that the set of factor allocations consistent with equilibria without complete agglomeration is larger using these assumptions compared to when firms do not have the option of becoming multinationals. This result suggests that, as the firms' get more options with regards to the location decision, the tendency for economic activity to agglomerate is weakened. The choice faced by the firm is no longer simply whether to locate in one region or in the other, but, instead, there is a third alternative; to locate in both regions.

However, there may also be another aspect of giving the firm more options with regards to location. When the firm can choose to locate different types of activities in different locations, there may be a tendency for certain types of activities to agglomerate. For example, headquarter activities such as developing products and processes through $\mathrm{R} \& \mathrm{D}$ may tend to be concentrated in regions with prominent universities or cities with a large pool of highly specialised labour. Production activities, on the other hand, may be concentrated in regions where product demand is especially high.

In this paper we study the effects on agglomeration tendencies of allowing firms to become multi-region firms, i.e. firms that locate activities in more than one region. To this end, we use the core-periphery (CP) model developed by Krugman (1991) and modify it to allow firms to have activities in both of two regions. We focus on two cases: First, horizontal multi-region firms are introduced by assuming multiplant economies of scale that make it less costly to set up a second plant than to set up a whole new firm. Second, vertical multi-region firms are introduced by allowing a separation of the location of the fixed and the variable production cost. We will interprete the fixed costs as headquarters and the variable cost as the cost of actual production. 
In the original CP-model, where labour is assumed mobile between regions, a symmetric equilibrium with total industrial production divided equally between two otherwise identical regions is stable for trade costs over a threshold level. The introduction of horizontal multi-region firms lead to less agglomeration in the sense that production will spread to both regions for a larger range of trade costs. In other words, the threshold level below which a core-periphery equilibrium emerges is lower with horizontal multi-region firms than in the original CP model.

With vertical multi-region firms headquarters will always move to the region with lower nominal wages. Thus, one effect of the introduction of vertical multiregion firms is to destabilise the completely symmetrical equilibrium. However, there is also another effect. For a firm that considers moving production to the peripheral region, the total cost of compensating workers for a higher price level in that region is smaller when headquarters can be retained in the core region. Therefore, with vertical multi-region firms, it becomes relatively cheaper to move production out of the agglomerated region. This effect will work against full agglomeration.

All in all, we draw the conclusion that as we make the firm's decision whether to become a single-region or multi-region firm endogenous, we get outcomes that are more consistent with observations on locational patterns. When firms can become vertical multi-region firms, changes in trade costs produce more gradual changes in the location of industrial activity and the long-term equilibra may very well be asymmetric in spite of underlying symmetry in the parameters of the model. Furthermore, the headquarters exhibit stronger tendencies to agglomerate than actual production.

The rest of the paper is organised as follows: In section 2, the model with horizontal multi-region firms is presented and the stability of the symmetric equilibrium analysed. In section 3, vertical multi-region firms are introduced and we analyse how this affects the stability of equilibria for different levels of trade costs. In section 4, the results generated by the analysis are discussed, and, finally, in section 5, we summarise our conclusions. 


\section{Horizontal Multi-Region Firms}

\section{The Model}

There are two regions in the economy; region 1 and 2; and two types of labour; farmers and workers. Farmers are immobile and produce a freely traded homogenous good with a unit labour input coefficient equal to one. We take this good as numeraire so that the wage in this sector equals one. Workers produce differentiated products and can move between the regions.

Individuals derive utility from a utility function of the following form:

$$
U=\mathrm{C}_{M}^{\mu} C_{A}^{1-\mu} ; \quad C_{M}=\left(\sum_{i=1}^{N} c_{i}^{1-1 / \sigma}\right)^{\frac{1}{1-1 / \sigma}}
$$

where $C_{A}$ is the consumed quantity of the homogenous agricultural good, $C_{M}$ is the consumed quantity of a CES-index of manufactured products, $\mathrm{N}$ is a large number of potential products and $\sigma>1$ the elasticity of substitution between each pair of manufactured products. The parameter $\mu$ is the constant share of expenditure on manufactured goods. The total population is normalised to one and we follow Krugman (1991) in assuming that there are $\mu$ workers and 1- $\mu$ farmers, which ensures that farmers and workers earn the same wage rate in long-run equilibrium in the $\mathrm{CP}$ model. Furthermore, farmers are equally divided between the two regions, ensuring a minimum size of demand for manufactures in each region.

In this section we assume that setting up a single-plant firm entails a fixed cost that consists partly of costs for headquarter activities such as $\mathrm{R} \& \mathrm{D}$, management and marketing and partly of fixed costs involved in setting up a production plant. However, the firm may choose to set up a second plant as well, in which case it will have to incur an additional fixed cost. If it does choose to set up two plants, each located in different regions, the total fixed costs are divided equally between the two 
regions in which the firm operates. The cost function of a horizontal multi-region firm can then be expressed as:

$$
w_{j} L_{i j}+w_{k} L_{i k}=\frac{\left(\alpha+\gamma^{h}\right)}{2}\left(w_{j}+w_{k}\right)+\beta\left(x_{i j} w_{j}+x_{i k} w_{k}\right)
$$

where $j=1,2, k=1,2, j \neq k, w_{j}$ and $w_{k}$ are the wage rates in region $j$ and $k$, respectively, $L_{i j}$ and $L_{i k}$ are the amounts of workers used by firm $i$ in region $j$ and $k$, respectively, $\alpha$ is the fixed cost in terms of workers for setting up a single-region firm while $\gamma^{h}$ is the additional fixed cost for setting up a second plant, $\beta$ is the marginal cost, and $x_{i j}$ and $x_{i j}$ are the output levels of firm $i$ in region $j$ and $k$, respectively. We assume that $\gamma^{h}<\alpha$ which implies that there are multiplant economies of scale.

Shipments of manufactured goods between regions are assumed to require trade costs of the iceberg type. To deliver one unit of $x$ to the other region, $\tau>1$ units have to be shipped. Agricultural goods, on the other hand, are traded without costs, which means that the price of agricultural goods is equalised between the two regions.

The manufacturing firms are assumed to operate under Chamberlinian large group competition, and a typical firm producing in region $j$ will set price as a mark-up on marginal cost according to:

$$
p_{k}=\left(\frac{\sigma}{\sigma-1}\right) \beta w_{j}
$$

where $p_{k}$ is the producer price on products sold in region $k$. Choosing units so that $\beta=(1-1 / \sigma)$ implies that $p_{k}=w_{j}$. However, the price that faces the consumer has to include any trade costs involved. This means that an exporting firm that charges the price $p_{k}$ on its deliveries to the home market will charge $\tau p_{k}$ on its exports to the other region.

The choice between becoming a single-region and a multi-region firm is modelled as a complementary slackness problem. As long as there are profits to be 
made from becoming one or the other type of firm, there will be entry into this type. In equilibrium, profits will be less than or equal to zero, with equality applying for any firm type that is active (cf. Markusen and Venables, 1998). Formally, we assume that the following inequalities hold:

$$
\begin{aligned}
& \frac{\left(x_{j j}+\tau x_{j k}\right)}{\sigma}-\alpha \leq 0 \\
& \left(\frac{x_{j j}}{\sigma}-\frac{\alpha+\gamma^{h}}{2}\right) w_{j}+\left(\frac{x_{k k}}{\sigma}-\frac{\alpha+\gamma^{h}}{2}\right) w_{k} \leq 0
\end{aligned}
$$

where $x_{j j}\left(x_{k k}\right)$ is the quantity sold by a firm producing in $j(k)$ in its domestic market, while $x_{j k}\left(x_{k j}\right)$ is the quantity sold by a firm producing in $j(k)$ in region $k$ 's $(j$ 's) market. ${ }^{1}$ The complementary variable for equation (3) is $n_{j}$, the number of singleregion exporting firms in region $j$ and the complementary variable for equation (4) is $m$, the number of multi-region firms active.

Market-clearing for the manufacturing sector implies that delivered quantities equal demand:

$$
x_{j j}=\frac{p_{j}^{-\sigma} \mu Y_{j}}{P_{j}^{1-\sigma}} \quad x_{j k}=\frac{\left(\tau p_{j}\right)^{-\sigma} \mu Y_{k}}{P_{k}^{1-\sigma}}
$$

where $j=1,2 ; k=1,2 ; j \neq k ; Y_{j}$ and $Y_{k}$ are total incomes in region $j$ and $k$, respectively; and $\mathrm{Pj}$ is the CES price index of manufactured goods for consumers in region $j$. The income of region $j$ is given by:

$$
Y_{j}=\frac{1-\mu}{2}+w_{j} \lambda_{j} \mu
$$

\footnotetext{
${ }^{1}$ In deriving (3) and (4) we have utilised the equality between producer prices and wages.
} 
where $\lambda_{j}$ is the share of the total number of workers that can be found in region $j$, i.e., $\lambda_{j}=L_{j} /\left(L_{1}+L_{2}\right)$. The price index is defined as:

$$
P_{j} \equiv\left(\left(n_{j}+m\right) p_{j}^{1-\sigma}+n_{k}\left(\tau p_{k}\right)^{1-\sigma}\right)^{1 /(1-\sigma)}
$$

Factor-market clearing implies that the total demand for workers has to equate total supply in each region $j$ :

$$
L_{j}=n_{j}\left(\alpha+\beta\left(x_{j j}+\tau x_{j k}\right)\right)+m\left(\frac{\alpha+\gamma^{h}}{2}+\beta x_{j j}\right)
$$

For a given supply of workers in the two regions, the system of equations and inequalities specified by (2) - (8) determine equilibrium values of the number of active firms of each type, wages, prices, delivered quantities to different regions and total incomes.

A manufacturing firm will have incentive to locate production in both regions in order to avoid trade costs. However, the gain from saving on trade costs has to be weighed against the additional fixed costs that have to be incurred in order to become a multi-region firm. If no firm chooses to become a multi-region firm, we have in fact the original CP-model. Hence, in order for the analysis to yield any new results, trade costs and multiplant economies of scale have to be such that some firms will find it advantageous to become multi-region firms.

\section{Stability Analysis}

The standard way of analysing the stability of an equilibrium in this model is to move one unit of manufacturing labour to the other region, let firms enter and exit, and thereafter compare the real wage in the two regions (e.g., Krugman, 1991). If the real wage in the receiving region is higher, even more workers will want to move there, which implies that the initial equilibrium is unstable. If the real wage in the receiving 
region instead is lower, the workers have incentives to move back to the region from which they came. This implies that the initial equilibrium is stable. ${ }^{2}$

The real wage $\omega$ of each region $j$ is given by,

$$
\omega_{j} \equiv w_{j} P_{j}^{-\mu}
$$

where, again, $P_{j}$ is the CES price index of manufactured goods for consumers in region $j$.

\section{\{Figure 1 about here\}}

Figure 1 shows the relationship between relative real wages and the relative size of regions in the original CP model with $\sigma=4$ and $\mu=0.3$. For $\tau=1.6$ the relative real wage of region 1 increases with an increased share of the total amount of workers located in that region. Thus, as soon as we are out of the symmetric equilibrium, workers have an incentive to move to the larger region. The symmetric equilibrium is therefore in this case unstable.

For $\tau=1.7$ we have the opposite relationship between relative wages and agglomeration. The relative real wage of region 1 decreases as it holds a larger fraction of the total supply of workers. In this case, the symmetric equilibrium is therefore stable. For intermediate trade costs, such as $\tau=1.65$, the model displays two additional asymmetrical and unstable equilibria. These bifurcations are characteristic of this type of model (see Fujita, Krugman and Venables, 1998).

In a model where firms are allowed to become multi-region firms, the configuration of firm types in equilibrium will be endogenously determined. This makes it even more difficult to arrive at analytical solutions than in the standard models of the so-called "new" economic geography. However, some analytical results

\footnotetext{
${ }^{2}$ An alternative, and equivalent, method of judging stability in the CP-model (e.g., Puga, 1997) is to move one firm to the other region, letting labour migrate to equalise real wages, and thereafter evaluate whether the profit is higher in the receiving region.
} 
are available. To begin with, we can show that when trade costs are sufficiently high and the additional fixed costs for setting up a second plant sufficiently low, there will only be multi-region firms in the symmetric equilibrium (cf. Horstmann and Markusen, 1992, Brainard, 1993). In the symmetric equilibrium, the endogenous variables will take identical values for the two regions, and, thus, we can drop the region indices. Furthermore, it is easily verified that in this equilibrium $w_{1}=w_{2}=1$. Profits can then be written as:

$$
\begin{aligned}
& \pi^{s}=\frac{\mu}{\sigma\left(m+n\left(1+\tau^{1-\sigma}\right)\right)}\left[\frac{1+\tau^{1-\sigma}}{2}\right]-\alpha \\
& \pi^{m}=\frac{\mu}{\sigma\left(m+n\left(1+\tau^{1-\sigma}\right)\right)}-\alpha-\gamma^{h}
\end{aligned}
$$

where $\pi^{s}$ and $\pi^{m}$ are profits for single-region and multi-region firms, respectively.

These expressions reveal that the multi-region firms have higher variable profits, on the one hand, but higher fixed costs, on the other. Whether profits will be higher for multi-region firms than for single-region ones will thus depend on this trade-off. By using the expressions in (9) and (10), we find that $\pi^{m} \geq \pi^{s}$ if:

$$
\gamma^{h} \leq \frac{\mu\left(1-\tau^{1-\sigma}\right)}{\sigma 2\left(m+n\left(1+\tau^{1-\sigma}\right)\right)}
$$

which by using the factor-market clearing condition can be simplified to:

$$
\frac{\gamma^{h}}{\alpha} \leq \frac{\left(1-\tau^{1-\sigma}\right)}{\left(1+\tau^{1-\sigma}\right)}
$$

for either $n=0$ or $m=0$. Setting both $\pi^{m}$ and $\pi^{s}$ to zero reveals that for both firm types to be active in equilibrium (i.e., $n, m>0$ ), the condition in (12) must hold with equality. The right hand side of (12) is bounded between zero and one and increasing 
in $\tau$. This implies that as the additional fixed cost of becoming a multi-region firm approaches the fixed cost of a single-region firm, $\alpha$, the condition in (12) is unlikely to be satisfied and there will be only single-region firms. On the other hand, as trade costs goes to infinity, which implies that the expression on the right hand side approaches one, (12) is likely to be satisfied as an inequality and there will be only multi-region firms.

From this we conclude that for multi-region firms to be active in the symmetric equilibrium, the degree of multiplant economies of scale as well as the level of trade costs have to be sufficiently high. Is it possible that even if there are no multi-region firms in the symmetric equilibrium, they will enter into the analysis as regions become dissimilar? No, the multi-region strategy will always be more advantageous when the regions are of similar size. Single-region firms will in this case export a fairly large fraction of their output. Thus, the saving on trade costs for a multi-region firm is the largest in this situation. Therefore, if no multi-region firms enter in the symmetric equilibrium, they will never enter and the analysis becomes identical to the one generated by the original CP-model.

Let us focus on the case where there are only multi-region firms in the symmetric equilibrium, i.e. the case where the condition in (12) holds as a strict inequality. How is the analysis affected as compared to the original CP-model? One important way in which the analysis differs from the one generated by the original CPmodel is that there is no trade in the symmetric equilibrium. All manufacturing varieties are produced in both regions. This implies that there are no agglomeration forces at work as long as we do not get entry of single-region firms. With only multiregion firms active, supply and demand linkages are absent because neither the price index nor the nominal wage will be affected by any changes in imports.

The fact that the predominance of multi-region firms removes any potential agglomeration forces suggests that they should have a stabilising effect on the symmetric equilibrium. However, since multi-region firms will exist only if trade costs are relatively high, i.e. when the symmetric equilibrium tend to be stable in the 
original CP-model, it is not completely clear that this will be the case in practice. However, our simulation results reveal that there are in fact cases where the original $\mathrm{CP}$-model produces the core-periphery outcome, while the model with horizontal multi-region firms yields a stable symmetric equilibrium.

\section{\{Figure 2 about here\}}

Figure 2 shows results for the model with horizontal firms at $\tau=1.6$, i.e., a level of trade costs where the symmetric equilibrium is unstable in the original CP-model. The results have been simulated for the same parameter values as in Figure 1 and the additional parameter $\gamma^{h}$ has been set to $0.2 \alpha$ (i.e., we have assumed a relatively high degree of multiplant economies of scale). ${ }^{3}$ The first thing to note about this diagram is that in the symmetric equilibrium, only multi-region firms are operating. Hence, the condition in (12) is satisfied as a strict inequality.

Furthermore, a reallocation of workers from one region to another will reduce the relative real wage of the region that becomes larger, i.e., the symmetric equilibrium is stable. At first, as we reallocate workers around the symmetric equilibrium multi-region firms continue to be the only firm-type active. Here, the change in the supply of workers leads to a sharp fall in the relative real wage of the larger region. Since all varieties are produced in both regions the price index will only depend the nominal wage in the region and the number of varieties that are produced. In fact, the relative real wage is given by

$$
\frac{\omega_{1}}{\omega_{2}}=\left(\frac{w_{1}}{w_{2}}\right)^{1-\mu},
$$

\footnotetext{
${ }^{3}$ The simulations have been run in GAMS which is able to handle complementarity problems (see Rutherford, 1994).
} 
which reveals that it will change in the same direction as the relative nominal wage. The nominal wage will fall in the region that becomes larger (and rise in the other region), since there are no demand and supply linkages that could strengthen the demand for workers in the larger region. By solving for $w_{1}$ using the factor market clearing condition in (8) we find that

$$
w_{1}=\frac{\mu(1-\mu)(\sigma-1)}{2 \lambda_{1} \mu(\sigma-\mu(\sigma-1))-m \sigma\left(\alpha+\gamma^{h}\right)} .
$$

This expression reveals that the nominal wage in region 1 falls as $\lambda_{1}$ increases, i.e. as region 1 holds a larger fraction of the total supply of workers. ${ }^{4}$

As we make regions even more dissimilar in size, eventually it becomes profitable to concentrate production in the larger region. That is, eventually there will be entry of single-region firms in the larger region. All firms will in that situation sell a fairly small part of their output in the smaller region, and, thus, the multi-region strategy becomes less advantageous. However, some firms will still find it profitable to save on trade costs by producing locally in both regions, thus becoming multiregion firms.

The entry of single-region firms introduces agglomeration forces into the model. The single-region firms have better access to their domestic market than to the other one. This means that as domestic demand increases relative to foreign demand, the firms can afford to pay higher nominal wages (demand linkage). At the same time, the induced increase in the number of locally produced varieties tends to lower the price index on manufacturing products (supply linkage). This contributes to raising the relative real wage of the expanding region. As can be verified from Figure 2, this is what happens as we successively reallocate workers from the smaller to the larger region.

\footnotetext{
${ }^{4}$ The corresponding expression for $w_{2}$ shows that the wage rate in region 2 rises with $\lambda_{1}$.
} 
In the particular case shown in Figure 2, the increase in the relative real wage of the larger region is not large enough to bring the model to a new equilibrium where real wages are fully equalised. However, in those cases where potential agglomeration forces are stronger, we may get unstable equilibria in between the symmetric equilibrium and the core-periphery outcome. Our simulation results show that, with the parameter values chosen in Figure 2, such unstable equilbria arise when $\tau$ lies in the range between 1.15 and 1.27. As we lower $\tau$ below 1.15, trade costs are too low for any firms to find it advantageous to produce in both regions, so there will only be single-region firms active. We then get the same long-run outcome as in the original $\mathrm{CP}$-model, i.e. the core-periphery solution.

\section{\{Figure 3 about here\}}

Another example where we get unstable asymmetric equilibria is shown in Figure 3, where the degree of multiplant economies of scale has been assumed to be relatively low. ${ }^{5}$ In this case, the symmetric equilibrium, which again is dominated by multi-region firms, is only locally stable. As regions diverge in terms of size, there will be entry of single-region firms from both regions, creating demand and supply linkages which tend to raise the relative real wage of the larger region. Here, these linkages are strong enough to raise the curve showing the relative real wage above the level where real wages are equalised, thus creating unstable asymmetric equilibria.

As is evident from Figure 3, as regions becomes less and less similar, eventually there will only be single-region firms active, some of them originating in the smaller region. This is a consequence of the property that the advantages of producing in both regions become smaller the more asymmetric regions get. For relatively low trade costs and very asymmetric regions, the advantage of producing in

\footnotetext{
${ }^{5}$ We have chosen $\gamma^{h}=0.6 \alpha$, but otherwise the same parameter values as in the previous figure.
} 
both regions may not be large enough to outweigh the extra fixed cost associated with production in two regions, and so single-region firms will dominate in equilibrium.

In this case, with a relatively low degree of multiplant economies of scale, there are two types of locally stable equilibria: a symmetric one dominated by multiregion firms and a completely agglomerated one, with all manufacturing firms located in one region, exporting to a peripheral region. The original CP-model, on the other hand, would only generate one type of stable equilibrium for these parameter values: a core-periphery equilibrium (i.e. the symmetric equilibrium would be globally unstable). Therefore, the results still suggest that the introduction of horizontal multiregion firms leads to a stabilisation of the symmetric equilibrium.

To sum up, if trade costs as well as the degree of multiplant economies of scale are relatively low, we tend to get the core-periphery outcome since firms tend to prefer to become single-region exporting firms. However, if multiplant economies are important, multi-region firms will enter into the analysis, stabilising the symmetric equilibrium. In such a case, trade liberalisation in the form of a successive lowering of trade has to go further to yield agglomeration of industrial activity compared with the original CP-model.

\section{\{Figure 4 about here\}}

The effect on long-term equilibria is shown in Figure 4. To the left of $\tau_{\mathrm{s}}$ (the so-called sustain point) the core-periphery outcome is supported by the original $\mathrm{CP}$ model. To the left of $\tau_{\mathrm{b}}$ (the so-called break point), the symmetric equilibrium is unstable in this model. In between $\tau_{\mathrm{b}}$ and $\tau_{\mathrm{s}}$, the symmetric equilibrium is locally, but not globally, stable. The effect of introducing horizontal multi-region firms is to push both $\tau_{\mathrm{b}}$ and $\tau_{\mathrm{s}}$ to the left. Thus, the symmetric equilibrium, now dominated by multiregion firms, is stable for a larger range of trade costs.

We can also note that, for a given level of trade costs, the degree of multiplant economies of scale will have a similar effect as trade costs on the location of 
production. For a high degree of multiplant economies of scale, the symmetric equilibrium will be stable. As we lower the degree of multiplant economies of scale, first the symmetric equilibrium will become only locally stable, and then we will get the core-periphery outcome. An implication of this is that we can imagine a situation where regional integration reduces trade costs, but because the degree of multiplant economies of scale are increasing at the same time, a dispersed production structure continue to be supported.

\section{Vertical Multi-Region Firms}

\section{The Model}

We now turn to exploring a model where we allow vertical multi-region firms, i.e., firms that can split their activities and locate them in different regions. To keep the model as simple as possible, we will only make a distinction between headquarter activities and production of the final products; thus, we will not consider any intermediate stages of production. ${ }^{6}$ Furthermore, we will associate headquarter activities with the fixed cost of setting up a firm. If the firm chooses to locate actual production and headquarters in different regions, it has to incur an additional fixed cost. This fixed cost is intended to capture any additional costs for communication that may arise as headquarters and production plants are geographically separated.

The firms have to decide whether to produce as a local firm, exporting to the other region, or to become a vertical firm that is headquartered in one region but produces in the other. If the firm decides to be a vertical firm, it also has to decide where to locate production and where to locate the headquarters (i.e. where to incur the fixed costs). Furthermore, if it decides to become a vertical firm, it will export some of its output back to its home region.

\footnotetext{
${ }^{6}$ This makes our multi-region firms similar to the ones considered by Helpman (1984) in his analysis of multinational firms in the context of a monopolistic competition trade model without trade costs (see also Helpman and Krugman 1985, Chapter 12).
} 
The fixed cost $\alpha$ is now interpreted as fixed costs for headquarter services only and we assume the following cost function for vertical multi-region firms:

$$
w_{j} L_{i j}+w_{k} L_{i k}=\alpha w_{j}+\gamma^{v} w_{j}+\beta x_{i k} w_{k} ; j=1,2 ; k=1,2 ; j \neq k
$$

where $\gamma$ is the additional fixed cost that has to be incurred in order to locate production and headquarters in different regions. Region $j$ is assumed to be the region where headquarters are located, while $k$ is the region where actual production takes place.

The complementary slackness equation for $m_{j}$ can now be written as:

$$
\frac{\left(x_{k k}+\tau x_{k j}\right)}{\sigma} w_{k}-\left(\alpha+\gamma^{v}\right) w_{j} \leq 0
$$

and the factor-market clearing conditions as:

$$
L_{j}=n_{j}\left(\alpha+\beta\left(x_{j j}+\tau x_{j k}\right)\right)+m_{j}\left(\alpha+\gamma^{v}\right)+m_{k} \beta\left(x_{j j}+\tau x_{j k}\right)
$$

Furthermore, the price index has to be redefined as

$$
P_{j} \equiv\left(\left(n_{j}+m_{k}\right) p_{j}^{1-\sigma}+\left(n_{k}+m_{j}\right)\left(\tau p_{k}\right)^{1-\sigma}\right)^{1 /(1-\sigma)} .
$$

\section{\{Figure 5 about here $\}$}

\section{Stability Analysis}

Figure 5 shows a typical simulation when we allow for vertical multi-region firms. To begin with we can note that in the symmetric equilibrium, there will only be singleregion firms active. When production costs are identical across regions, the firms will 
have no incentives to split up headquarters and production activities. However, as we reallocate workers from one region to the other, such incentives may arise.

The output from headquarter activities can here be regarded as a good that is freely traded (within the firm). Therefore, the firms will choose to locate headquarters where production costs are the lowest, i.e., they will choose to locate headquarters in the region with the lower nominal wage. The difference in costs must however be large enough to compensate for the additional fixed cost that has to be incurred when splitting up headquarters and production. This means that, in a region close to the symmetric equilibrium, where the difference in nominal wages is not sufficiently large, only national firms will exist.

As regions become more dissimilar, however, vertical multi-region firms will enter. To determine the location of their headquarters, we have to determine which region has the lower nominal wage. The critical condition can be derived in the following way: Let us start out in the symmetric equilibrium where we know that the only firm type active will be single-region firms. From the zero-profit condition follows that output levels per firm are constant. If we substitute for the demand functions we get the following so-called wage equation for region- $j$ firms:

$$
w_{j}=\left(\frac{Y_{j}}{P_{j}^{1-\sigma}}+\frac{\tau^{1-\sigma} Y_{k}}{P_{k}^{1-\sigma}}\right)^{\frac{1}{\sigma}}
$$

where, for simplicity, we have chosen units so that $\alpha=\mu / \sigma$. Differentiation of this expression yields:

$$
\sigma d w_{j}=2 z d Y_{j}-z \frac{d\left(P_{j}^{1-\sigma}\right)}{P_{j}^{1-\sigma}}
$$

where $z=\left(1-\tau^{1-\sigma}\right) /\left(1+\tau^{1-\sigma}\right)$.

Differentiation of the nominal income in region $j$ yields: 


$$
d Y_{j}=\mu d \lambda_{j}+\frac{\mu}{2} d w_{j}
$$

Finally, differentiation of the price index yields:

$$
\frac{d\left(P_{j}^{1-\sigma}\right)}{P_{j}^{1-\sigma}}=z(1-\sigma) \mathrm{d} w_{j}+2 z \mathrm{~d} \lambda_{j}
$$

By substituting for changes in income and price levels in the differentiated constant total demand condition, we get:

$$
\frac{\mathrm{d} w_{j}}{\mathrm{~d} \lambda_{j}}=\frac{2 z(\mu-z)}{\sigma\left(1-z^{2}\right)-z(\mu-z)}
$$

Since the denominator of the right hand side of (21) is always positive, a necessary and sufficient condition for the whole expression to be negative is that $\mathrm{z}>\mu{ }^{7}$ Using the definition of $z$ the condition can also be written as:

$$
\tau>\left(\frac{1+\mu}{1-\mu}\right)^{\frac{1}{\sigma-1}}
$$

The condition in (22) reveals that if trade costs are low and/or the share of manufacturing products in total spending high, nominal wages may increase rather than decrease in the larger region. Agglomeration forces are in this case particularly strong. Therefore, the reallocation of workers not only increases the real wage in the receiving region, but the nominal wage as well.

\footnotetext{
${ }^{7}$ Note that the denominator is increasing in $\sigma$. If we evaluate the denominator at $\sigma=1$, we get $1-z \mu$. This expression is positive since $z<1$ and $\mu<1$. Consequently, the denominator must be positive for all possible values of $\sigma>1$.
} 
In the case shown in Figure $5, z>\mu$, so that nominal wages would fall in the larger region as we reallocate workers away from the symmetric equilibrium, given that firms were prevented from choosing the multi-region strategy. If we do allow firms to become vertical multi-regional firms, headquarters and production activities do not have to enter and exit in fixed proportions. Because of the incentives for firms to locate headquarters where nominal wages are the lowest, there will be more entry of headquarters and less of production activities in the larger region. Hence, there will be a tendency of agglomeration of headquarters in the larger region. However, the proportion in which headquarter and production activities enter and exit will be such that nominal wages remain equalised, except for a constant difference related to the additional fixed $\cos \gamma^{\mathrm{v}}$.

The reallocation of headquarters is in effect a reallocation of an activity that produces a homogenous good (or, more appropriately, a homogenous service) that is traded without cost. As long as both regions continue to produce this service, factor prices will be equalised except for the constant additional fixed cost that has to be compensated for by a lower wage in the larger region. Therefore, relative nominal wages will be unaffected by reallocations of workers between the two regions as long as there is not complete specialisation in headquarter activities.

As shown in Figure 5, there is a range around the symmetric equilibrium for which the difference in nominal wages is not large enough to induce firms to become multi-regional. Our model therefore behaves as the $\mathrm{CP}$-model for this range of factor allocations. Outside this range, a small increase in one region's share of the total supply of workers produces an increase in the relative real wage of that region. As already explained, nominal wages are unaffected by such reallocations. ${ }^{8}$ The price index, on the other hand, is affected by the change in the relative importance of locally produced varieties. It decreases in the larger region and increases in the smaller region. Consequently, the relative real wage increases in the larger region.

\footnotetext{
${ }^{8}$ That is, they are unaffected after an initial effect whereby the large region's nominal wage falls by a constant amount related to $\gamma^{v}$.
} 
However, when we reach the point where all headquarters have moved to the larger region, marked by a kink in the curve, further reallocations of workers will lead to a fall in the relative nominal wage of the larger region. We are then in a situation where headquarters and production activities exit and enter in fixed proportions, just as in the original CP-model. Since $\mathrm{z}>\mu$, the nominal wage will fall in the larger region. Moreover, according to our simulation results, the nominal wage falls more than the price index, which implies that the real wage in the larger region is now decreasing. In the smaller region, the nominal wage starts to increase and this contributes to a fall in the relative real wage of the larger region. In Figure 4, the relative real wage curve crosses the horizontal line where real wages are equalised at allocations in between those of complete symmetry and core-periphery. Since the curves cut the horizontal line from above, these equilibria are stable.

From this we may conclude that the introduction of vertical firms have a destabilising effect on the symmetric equilibrium in the sense that, outside the small range where only single-region firms exists, it becomes unstable also for very high trade costs. However, the introduction of vertical firms will at the same time have an effect in the direction of weakening agglomeration tendencies in the sense that the parameter space for which we get the core-periphery outcome is reduced. While the CP-model leads to complete agglomeration for $\tau=1.6$ (see Figure 1), the model with vertical multi-region firms produces a stable equilibrium with 12-13 percent of manufacturing production in the smaller region. In order for complete agglomeration to occur in the model with vertical firms, trade costs again have to be lower than in the original CP model.

The weakening effect on agglomeration tendencies can be explained as follows: In order to start producing in the smaller region firms must attract workers by paying a higher nominal wage to compensate for the higher price index. When firms can split production and headquarters it becomes cheaper to move production into the smaller region, since the firm can then go on paying the lower nominal wage to headquarter workers that stay in the larger region. It will therefore be profitable to 
break away from full agglomeration at a lower trade cost than in the CP-model. Similarly, the potential cost saving from moving production into the larger region is less with vertical multi-region firms since the headquarters are already located in that region.

\section{\{Figure 6 and 7 about here $\}$}

Figure 6 shows the effect of trade liberalisation when vertical firms are allowed. As trade costs are lowered, the stable equilibria will become more and more asymmetric, and, finally, they will slide all the way to complete agglomeration. Agglomeration is thus a gradual process rather than the catastrophical event that occurs in the original CP-model as soon as trade costs fall below some threshold level.

Finally, we shall deal with the case when $\mathrm{z} \leq \mu$; that is, the case where a small reallocation of workers tend to increase rather than decrease the nominal wage in the region that becomes larger. Figure 7 shows simulation results for $\mathrm{z}<\mu$. Consider first the curve for $\tau=1.22$. This is the case where $\mathrm{z}$ is very close to $\mu$. Here, the nominal wage changes very little as workers are reallocated between the regions. Therefore, it never pays for a firm to incur the additional fixed cost $\gamma^{v}$ for splitting up headquarters and production facilities. Consequently, in this case no vertical firms arise at all. Instead, we are back to the case with single-region firms only, which, for this level of trade costs, yields a core-periphery structure in long-run equilibrium.

Second, consider the case where trade costs are lower than this, $\tau=1.1$. Now, nominal wages will tend to change more sharply as we reallocate workers between the regions. Nevertheless, just as in Figure 5 and 6, there is still a range around the symmetric equilibrium for which the difference in nominal wages is not enough to induce firms to become multi-region firms. However, as regions become sufficiently different in size, the difference in nominal wages becomes large enough for some firms to find it advantageous to separate geographically headquarters and production 
activities. Since the nominal wage now is lower in the smaller region, headquarters will be located in that region.

As this happens, to begin with, there will be single-region firms in both regions as well as multi-region firms with headquarters in the small region and production in the large region. Eventually, however, the smaller region becomes so small that it completely specialises in headquarter activities. Then, there will be no single-region firms operating in the small region any longer. At this point, the relative real wage curve becomes almost horizontal. With headquarters in both regions, the nominal wage is kept constant because factor price equalisation applies. However, all production now takes place in the large region. Therefore, further reductions in the size of the small region have very limited effects on the price indices of the two regions. The only thing that happens is that the total number of varieties increases somewhat as a consequence of a reduction of trade between the regions. ${ }^{9}$

In this case, where reallocations of workers tend to lower the nominal wage in the smaller region, headquarters will thus tend to agglomerate in that region when we take the allocation of workers as given. Because there will be headquarters in both regions, the nominal wage is however prevented from falling below the wage in the larger region with more than a factor corresponding to the additional fixed cost for splitting up headquarters and production. The price index, on the other hand, is decreasing with the size of a region as long as the relative importance of domestically produced varieties increases. This implies that the relative real wage becomes increasingly higher in the larger region as we successively make the regions more dissimilar in size, up to the point where all production gets concentrated in the larger region. Beyond that point, the relative real wage remains constant. All in all, this implies that, in the case where $\mathrm{z} \leq \mu$, the symmetric equilibrium is always unstable and we always get the core-periphery outcome in the long-run equilibrium.

\footnotetext{
${ }^{9}$ That is, real resources are saved when costly exports of manufacturing products from the larger region decrease.
} 
Thus, the introduction of vertical multi-region firms has two effects. First, it tends to destabilise the symmetric equilibrium because headquarters agglomerate in one region except for very symmetric factor allocations. ${ }^{10}$ Because headquarters tend to agglomerate while production tends to be more spread out, we typically get locally stable asymmetric equilibria when the original CP-model produces globally stable symmetric equilibria. In this sense, the introduction of vertical multi-region firms leads to more agglomeration than in the CP-model. However, just as in the case with horizontal multi-region firms, the range of trade costs for which we get full agglomeration is reduced compared to the original CP-model. In this sense, the introduction of vertical firms leads to less agglomeration.

\section{\{Figure 8 about here\}}

The long-term equilibria with vertical multi-region firms are shown in Figure 8. The symmetric equilibrium will be stable for exactly the same range of trade costs as in the CP-model. However, now the symmetric equilibrium will only be locally stable, because there will be stable asymmetric equilibria in between symmetry and core-periphery as well. As we reduce trade costs beyond the point where the symmetric equilibrium is stable, there will be some range of trade costs for which asymmetric equilibria are globally stable. However, with further reductions in trade costs, we eventually get the core-periphery outcome.

\section{Discussion}

The conclusions that we can draw from the analysis so far are the following: The introduction of horizontal multi-region firms weakens agglomeration tendencies and it does so to a greater extent the higher the degree of multiplant economies of scale. The

\footnotetext{
${ }^{10}$ The agglomeration of headquarters breaks the symmetry of the original CP-model. The effect is similar to what happens when the two regions are inherently asymmetrical because farmers are unequally divided.
} 
introduction of vertical multi-region firms has an ambiguous effect on the strength of agglomeration tendencies because, while headquarters tend to agglomerate irrespective of the level of trade costs, the actual production becomes in a sense more spread out.

It is evident that, in reality, firms that choose to operate in more than one location rarely are purely horizontal or purely vertical in nature. As we study the behaviour of actual multi-region firms, most often we find that there is an element of both present. In the analysis, however, we have isolated the effect of each form in order to distinguish between their separate effects.

One way of analysing the effect of introducing multi-region firms that to some extent are both horizontal and vertical would be to assume that the horizontal firms have a home country in which they incur the main part of their fixed costs. The choice of home country would then be affected by where nominal wages are the lowest, and, just as in the model with vertical firms, we would tend to get agglomeration of headquarters of multi-region firms. At the same time, the presence of multiplant economies of scale would tend to spread out production.

Our simulation results reveal that in such a case we may get stable equilibria in between the symmetric one and the core-periphery outcome, again, just as in the model with vertical firms. Furthermore, in situations where the symmetric equilibrium is stable, an element of indeterminacy is introduced in the sense that, initially, real wages are not affected by a reallocation of workers between the regions. A reallocation of workers from the symmetric equilibrium leads to a reallocation of headquarters between the regions, and, for each firm, a reallocation of its total output between its domestic and foreign plant. However, nominal wages and price levels are unaffected as long as there are only multi-region firms active in equilibrium. Thus, such a modification of the model with horizontal firms yields results that are in line with those found in the previous analysis -the introduction of multi-region firms tends to make production more spread out, headquarters more agglomerated and long-run equilibria more asymmetric. 


\section{Conclusions}

This paper has analysed the effects of allowing for a more general production structure in the core-periphery model. Two cases have been analysed: the cases with horizontal and vertical multi-region firms. In general, we find that the changes in production patterns as trade costs fall become less dramatic as we introduce endogenous multiregion firms. Horizontal multi-region firms are generally stabilising in the sense that they decrease the range of trade costs for which the core-periphery outcome occurs. This effect is more pronounced the higher the degree of multiplant economies of scale.

The case of vertical multi-region firms in which the location of headquarters activities is separated from the location of production is less clear-cut. Just as with horizontal multi-region firms, the range of trade costs for which full agglomeration occurs decreases. In this sense it leads to less agglomeration compared to the original $\mathrm{CP}$ model. However, there is also another effect that works in the opposite direction. Headquarters tend to agglomerate in one region, and this makes the symmetric equilibrium unstable. In this sense the introduction of vertical multi-region firms can be said to lead to more agglomeration. Thus, apart from just weakening the strong tendency of agglomeration of production found in the original CP-model, the introduction of multi-region firms generates a tendency for agglomeration of headquarter activities and for outcomes that lie in between the two extremes of complete symmetry and complete agglomeration.

In our analysis, changes in trade costs produce more gradual changes in the location of industrial activity compared to the original CP-model. Furthermore, longterm equilibra may very well be asymmetric in spite of underlying symmetry in the parameters of the model. Finally, headquarters exhibit stronger tendencies to agglomerate than actual production; a result that seems to be consistent with "casual empiricism". Activities such as R\&D and corporate management clearly seem to be 
more geographically concentrated than production activities in general. All in all, we thus draw the conclusion that as we make the firm's decision whether to become a single-region or multi-region firm endogenous, we get outcomes that are more consistent with the locational patterns that we observe in the real world. 


\section{References}

Baldwin R. and A. J. Venables (1996) "Regional Economic Integration". In Handbook of International Trade, Vol. III. Amsterdam: North-Holland.

Brainard, S. L. (1993), “A simple theory of multinational corporations and trade with a trade-off between proximity and concentration", NBER Working Paper No. 4269.

Helpman, E. (1984), "A simple theory of international trade with multinational corporations", Journal of Political Economy, 92, 451-471.

Helpman, E. and P. R. Krugman (1985), Market Structure and Foreign Trade: Increasing Returns, Imperfect Competition, and the International Economy, Cambridge, MA: MIT Press.

Horstmann, I. J. and J. R. Markusen (1992), "Endogenous market structure structures in international trade (natura facit saltum)", Journal of International Economics, 32, 109-129.

Fujita, M., P. R. Krugman, and A. J. Venables (1998), The Spatial Economy: Cities, Regions, and International Trade, mimeo.

Krugman P. R. (1991) "Increasing Returns and Economic Geography”, Journal of Political Economy 99, 483-99.

Krugman P. R. and A. Venables (1995) "Globalization and the Inequality of Nations", Quarterly Journal of Economics.60, 857-80.

Markusen J. R. and A. J. Venables (1996) “The Theory of Endowment, Intra-Industry and Multinational Trade", CEPR Working Paper No.1341.

Markusen J. R. and A. J. Venables (1998) "Multinational Firms and the New Trade Theory", forthcoming in Journal of International Economics.

Puga, D. (1997), Regional Integration and the Location of Economic Activity, Ph.D. dissertation, London School of Economics.

Rutherford, T. F. (1994), "Extensions of GAMS for Complementarity Problems Arising in Applied Economic Analysis", mimeo, Department of Economics, University of Colorado at Boulder. 